\title{
The coordination of health reception for refugee children in the Nordic countries
}

Barghadouch, A.; Michaelis, C.

Published in:

European Journal of Public Health

DOI:

10.1093/eurpub/cky213.879

Publication date:

2018

Document license:

Unspecified

Citation for published version (APA):

Barghadouch, A., \& Michaelis, C. (2018). The coordination of health reception for refugee children in the Nordic countries. European Journal of Public Health, 28, 300. https://doi.org/10.1093/eurpub/cky213.879 
collected national laws and guidelines related to the health reception of refugee children in Denmark, Finland, Norway and Sweden. 25 policies consisting of acts and professional guidelines on health, immigration, reception and integration were analysed. To fill in potential gaps in findings a keyinformant from each country was interviewed in October 2017.

Results:

Our study suggests that few health reception policies across the Nordic region primarily focus on refugee children. The identified policies chiefly recognize the rights of refugee children to somatic healthcare services and services to accommodate urgent health needs. Hence, initiatives promoting mental health and health-enabling contexts for refugee children were addressed to a lower extent, especially in Danish and Finnish policies.

\section{Conclusions:}

There is a need for a greater recognition of refugee children in national health reception policies. Further knowledge is however needed on whether and how these policies play out in health reception practices.

The coordination of health reception for refugee children in the Nordic countries

\section{A Barghadouch, C Michaëlis}

Danish Research Centre for Migration, Ethnicity and Health, Department of Public Health, University of Copenhagen, Copenhagen, Denmark

Contact: cch@sund.ku.dk

\section{Background:}

The rights of refugee children should be addressed explicitly in national policies that facilitate health reception initiatives. However, studies argue that especially refugee children arriving with their families may be overlooked in both policies and practices related to health. The purpose of this study is to map out, compare and contrast the focus of health reception policies in Denmark, Finland, Norway and Sweden, with a particular emphasis on how they specifically account for the rights and needs of refugee children.

Methods:

The material is drawn through desk-research conducted from January-September 2017, where we searched for and 